\title{
Optical investigation of prechamber combustion in an RCEM
}

In this study, detailed investigations of scavenged prechamber engine combustion are performed experimentally in a Rapid Compression Expansion Machine (RCEM), which allows optical access into the main chamber. OH* chemiluminescence measurements combined with pressure measurements are used to study the effect of varying ignition timing on combustion and cycle-to-cycle variations. The variation of ignition timing (pressure at ignition) showed an optimum ignition point for a given injection duration. Earlier ignition resulted in weaker but more reactive jets, coupled to increased cyclic variations. Later ignition did not significantly affect heat release rate, but increased cyclic variation.

Keywords: scavenged prechamber, optical measurements, ignition timing

\section{Introduction}

Efforts to reduce $\mathrm{CO}_{2}$ emissions from internal combustion engines have led to the use of natural gas as a fuel in lean-burn spark ignition engines [2]. Lean-burn, or alternatively high-dilution combustion concepts, are employed in order to keep engine efficiency high by minimizing thermal losses, while also keeping $\mathrm{NO}_{\mathrm{x}}$ emissions below legislated limits. Under high-dilution conditions, operation is limited by high cyclic variability as well as increased unburned hydrocarbon emissions [3, 17]. In order to address these limitations, external ignition engines require high ignition energy and distributed ignition sources in order to ignite and consume the lean/diluted premixed main charge [10,17].

A widely used technology in these engines is prechamber ignition systems, in which the external ignition source is located in a separate small volume, connected to the main chamber via orifices [3,17]. This setup allows the design for favorable ignition conditions near the ignition source, which result in fast and repeatable early flame propagation. The pressure difference resulting from combustion taking place inside the prechamber pushes jets containing active radicals and/or hot combustion products into the main chamber, which ignite the lean or diluted mixture. The use of prechamber ignition systems in engines allows the combustion of very lean/diluted mixtures, resulting in higher efficiencies and lower $\mathrm{NO}_{\mathrm{x}}$ emissions [17].

Research in the field of prechamber combustion has been extensive in the past years, aiming to increase our understanding and allow the practical application of such systems. Mamar et al. [1] worked on an optically accessible prechamber engine. They reported that a faster combustion was observed using a prechamber in comparison to open chamber ignition. Additionally, faster flame jets induced by higher pressure difference were claimed to reduce the main chamber combustion duration. Moreira et al. [9] analysed an unscavenged prechamber in a four cylinder engine. The unscavenged prechamber system was reported to lead to increased engine efficiency, as well as reduced $\mathrm{NO}_{\mathrm{x}}$ emissions and IMEP covariance.

More recently, Kotzagianni et al. [8] compared the scavenged and unscavenged operation modes of a prechamber and investigated the effect of injected fuel amount into the prechamber. The unscavenged operation resulted in slower and longer combustion in the main chamber. Concerning the fuel amount injected into the prechamber, when exceeding a certain amount, additional fuel had no significant impact on the combustion in the main chamber. Some numerical studies $[4-7,11,16]$ have studied the effect of turbulence generation in the prechamber. These report that the turbulence inside the prechamber dissipates very quickly between the end of the compression and the ignition; this results in slower jets when ignition timing is late in the cycle. In addition, accurate modelling of the turbulent quantities is important in order to correctly predict prechamber combustion and resulting jet presentation.

In this work, we aim to study the effect of spark timing on the combustion in the prechamber and the main chamber using optical diagnostics and pressure measurements. The purpose is to determine the effect of ignition timing on scavenged prechamber combustion and cycle-to-cycle variation. To this end, an optically accessible Rapid Compression Expansion Machine is used, where information concerning prechamber and main chamber combustion can be obtained through optical measurements. The paper starts with a description of the experimental setup and the measurement conditions chosen. This is followed by the results section, where the prechamber and main chamber combustion are studied, before a brief discussion about the findings and their relevance to scavenged prechamber engine operation. The paper closes with the conclusions of the work.

\section{Experimental setup and measurement conditions}

The current study was performed in a Rapid Compression Expansion Machine (RCEM). The RCEM operates in a single cycle mode (compression-expansion) and combines excellent optical access with high flexibility in independently changing parameters, such as mixture composition, start of ignition, initial chamber conditions, etc. The RCEM uses a free-floating piston, which is driven by a pneumatic-hydraulic system towards the cylinder head. This motion creates the compression stroke, while the increasing pressure due to compression and combustion eventually drive the piston back. The piston contains a quartz window, which allows optical access towards the cylinder head, where the different pre-chambers are mounted cen- 
trally. A UV-enhanced mirror is placed behind the quartz piston in order to allow the detection of the area where the reacting jets were exiting and the combustion inside the main chamber. A schematic of the RCEM, showing the most important components, is shown in Fig. 1. The most important technical characteristics are summarized in Table 1 , while further details about the driving part and the principle of operation of the RCEM can be found in [8, 12-14].

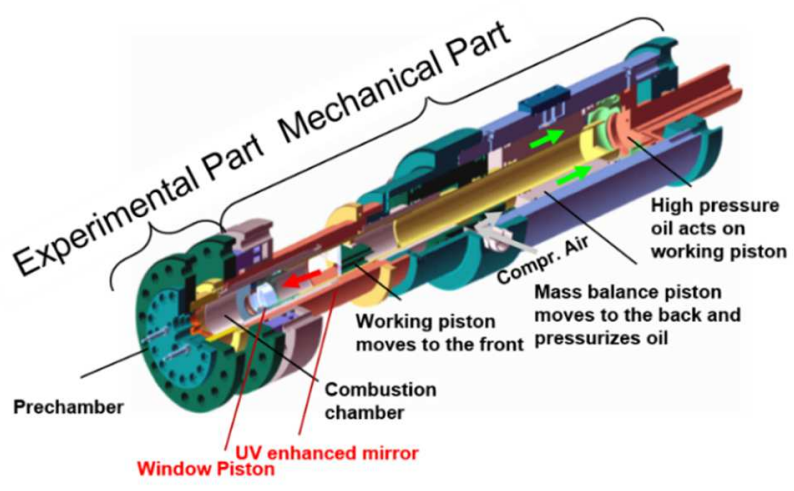

Fig. 1. Schematic of the RCEM, adapted from [15]

Table 1. Technical characteristics of the Rapid Compression Expansion Machine

\begin{tabular}{|c|c|}
\hline Parameter & Description \\
\hline Bore $(\mathrm{B})$ & $84 \mathrm{~mm}$ \\
\hline Stroke length (s) & $\begin{array}{c}\text { Adjustable from } 120-249 \mathrm{~mm} \\
\text { (here } 249 \mathrm{~mm} \text { ) }\end{array}$ \\
\hline Compression stroke $(\varepsilon)$ & $5-30$ \\
\hline Loading pressure $\left(\mathrm{P}_{\text {load }}\right)$ & $1-3$ bar (here 1.2 bar) \\
\hline Max. cylinder pressure $\left(\mathrm{P}_{\max }\right)$ & Up to 200 bar \\
\hline Piston bowl & $\begin{array}{c}\mathrm{d}_{\mathrm{b}}=52 \mathrm{~mm}, 2.2 \mathrm{~mm} \text { depth } \\
\text { (top hat) }\end{array}$ \\
\hline Piston optical access & $\mathrm{d}_{\mathrm{w}}=52 \mathrm{~mm}$, quartz window \\
\hline Heating system & $\begin{array}{c}\text { Cylinder head and cylinder liner } \\
\text { heating }\end{array}$ \\
\hline Ignition & $\begin{array}{l}\text { Spark plug mounted inside } \\
\text { the pre-chamber }\end{array}$ \\
\hline
\end{tabular}

The RCEM bore diameter is $\mathrm{B}=84 \mathrm{~mm}$ and the quartz piston has a top hat bowl shape with diameter of $52 \mathrm{~mm}$ and depth of $2.2 \mathrm{~mm}$. The piston stroke is adjustable ( $\mathrm{s}=$ $=120-250 \mathrm{~mm}$ ), and for this study was set at maximum. The temperature of the cylinder head and liner was set to $383 \mathrm{~K}$ using different heating elements and measured by 6 K-type thermocouples. Differently than in an engine, the filling process of the RCEM cylinder is occurring well before the compression and thus no turbulence exists in the main chamber at the beginning of the stroke.

The pre-chamber used is a prototype, and was positioned centrally and in a plane normal to the cylinder axis, similarly to its placement in an engine cylinder. The prechamber has 7 nozzles of $1.5 \mathrm{~mm}$ in diameter, which are placed at an angle to the cylinder axis in order to induce a swirling flow within the prechamber during compression.

The pressure measurements inside the main chamber were performed using a cooled piezoelectric pressure sensor (Kistler no. 7061B, 0-250 bar), which was coupled to a Kistler 5011 charge amplifier. An absolute piezoresistive pressure sensor (Kistler no. 4053, 0.0-5.0 bar) was employed for the pressure correction (pegging) of the piezoelectric pressure sensor. The absolute pressure sensor was connected to the cylinder through an automatic switching adaptor (Kistler 741A), which allowed the piezoelectric sensor pegging during the early stages of compression. The initial pressure inside the combustion chamber was set at 1.2 bar for all operating points. Additional piezo-resistive pressure sensors were mounted on the driving piston and the fuel supply line of the PC and MC to control the filling of the driving gas, which was set at 27 bar, and the fuel pressure for the PC and the MC, which were set to 10 and at 60 bar respectively. The synchronisation of all triggering signals, i.e. for the start of injection in the pre- and main chamber, the ignition timing and the image acquisition using the high speed camera, was achieved using a cylinder pressure-based system, which allows triggering at certain cylinder pressures.

The fuel for the filling of the main chamber was administered by a Siemens hollow cone piezo actuated injector, which was located $35 \mathrm{~mm}$ off-axis in the cylinder head. The piezo injector has an umbrella angle of 90 degrees and was operated with a nominal needle lift of $25 \mu \mathrm{m}$. The injection pressure was 60 bar. For safety reasons and in order to achieve a homogeneous background methane-air mixture, the gaseous methane was injected into the chamber filled with pure air $\left(\mathrm{P}_{\text {load }}=1.2\right.$ bar $)$ about 3 seconds bTDC and prior to the start of compression. The composition of the main chamber was set to $\lambda=2.0$ for all measurement points. The methane injection for filling the pre-chamber was performed using a prototype injector (EFF-Dunken KSV 017). The injector was supplied with fuel through a pre-chamber injector rail, and the rail pressure was kept constant at 10 bar throughout the experiments. The start of injection was performed during the compression, when the pressure of the main chamber reached 2.0 bar. The injection duration for the pre-chamber fuel filling was kept constant at $2.5 \mathrm{~ms}$ for this investigation. The fuel for the PC and MC was supplied from high purity methane bottles $(99.995 \%$ $\mathrm{CH}_{4}$ ). The ignition was initiated by an ignition coil (VW AG 06.J.905.110.G, BEO S3) with a G-type spark plug (NGK R - M10) which has a $0.5 \mathrm{~mm}$ gap. The pressure at ignition was varied between 15 and 30 bar. A description of the main parameters for the current measurements is shown in Table 2, which includes the main chamber air/fuel ratio, the prechamber injection duration, the set and measured average pressure at ignition and the average resulting ignition timing referenced to the top dead centre (TDC) point. All measurement points were repeated 12 times; the pressure results reported are the averages of the 12 repetitions.

Table 2. Operating conditions

\begin{tabular}{|c|c|c|c|c|}
\hline $\begin{array}{c}\text { Main } \\
\text { chamber } \lambda\end{array}$ & $\begin{array}{c}\text { PC injection } \\
\text { duration (ms) }\end{array}$ & $\begin{array}{c}\text { Set pressure at } \\
\text { Ignition (bar) }\end{array}$ & $\begin{array}{c}\text { Meas. av. pres. } \\
\text { at ignition (bar) }\end{array}$ & $\begin{array}{c}\text { Av. ignition } \\
\text { time bTDC } \\
(\mathrm{ms})\end{array}$ \\
\hline 2.0 & 2.5 & 15 & 14.9 & -5.12 \\
\hline 2.0 & 2.5 & 18 & 18.2 & -4.53 \\
\hline 2.0 & 2.5 & 23 & 23.1 & -3.31 \\
\hline 2.0 & 2.5 & 26 & 25.6 & -3.10 \\
\hline 2.0 & 2.5 & 30 & 29.6 & -2.59 \\
\hline
\end{tabular}


Information about the combustion characteristics of the flame/radical jets and the flame propagation inside the main chamber were acquired using high speed $2 \mathrm{D} \mathrm{OH} *$ chemiluminescence imaging. The spatial distribution of $\mathrm{OH}^{*}$ chemiluminescence was recorded with an intensified high speed camera at $32 \mathrm{kHz}$ repetition rate (LaVision HSSX and image intensifier, 10/12 bits dynamic range) equipped with a $50 \mathrm{~mm}$ UV lens (f/20) and a bandpass filter for a wavelength of $306 \mathrm{~nm}$ and $12.1 \mathrm{~nm}$ FWHM. The acquired 2D $\mathrm{OH}^{*}$ chemiluminescence images have been analysed using a purpose-built Matlab routine in order to obtain information about the jet exiting time.

\section{Results}

The study undertaken involves the variation of the spark timing with respect to TDC, which was achieved by varying the value of cylinder pressure when the ignition is triggered. The ignition was triggered at cylinder pressures from 15 to 30 bar, with steps of around 4 bar $(15,18,23,26,30$ bar). This variation is expected to have multiple effects on the prechamber combustion. The variation of pressure directly affects the thermodynamic conditions at ignition, since the pressure and temperature are correlated if we assume a near-adiabatic, closed system. The exact temperature at the ignition location is very difficult to be estimated since the heat losses, particularly within the prechamber, are unknown; nevertheless, the gas temperature is expected to be increasing with increasing pressure, resulting in a faster laminar flame speed (the increase of laminar flame speed with temperature is higher than the corresponding decrease with increasing pressure). In addition to this, during the compression stroke, as the main chamber pressure increases, more of the leaner main charge is pushed into the prechamber, increasing the average air to fuel ratio. This, along with the degree of homogenization of the prechamber which increases with time, is expected to have a significant effect on the flame speed in the prechamber. At earlier ignition timings the fuel-air mixture near the spark location is expected to be rich, while at later spark timings it is expected to be leaner. Finally, the turbulence intensity in the prechamber, which varies significantly with time due to the variable turbulence production from the incoming flow and the turbulence dissipation over time, is expected to mostly decrease with later ignition timings (i.e. with higher pressures at ignition).

In the present investigation three diagnostics are used to investigate the prechamber and main chamber combustion with different ignition timings. For the prechamber combustion, the jet emergence timing after ignition into the main chamber as the primary diagnostic. The earlier timing after ignition indicates faster combustion in the prechamber. For the main chamber combustion we use the main chamber optical images which give an indication of jet and flame reactivity, as well as the calculated main chamber heat release rate (HRR). The prechamber and main chamber combustion are presented separately in the subsections which follow. The results section closes with a discussion of the findings and an attempt to connect these results to engine operation.

\subsection{Prechamber combustion}

In this study we use the jet emergence timing after ignition into the main chamber as the primary diagnostic of the prechamber combustion. The jet exit timing is determined when a certain level of $\mathrm{OH}^{*}$ is visible in the main chamber. The level of $\mathrm{OH}^{*}$ was arbitrarily chosen to avoid measurement noise affecting the study. Figure 2 shows the jet exit timing in ms after the ignition timing, for the different ignition pressures and for each of the 12 repetitions at each pressure point.

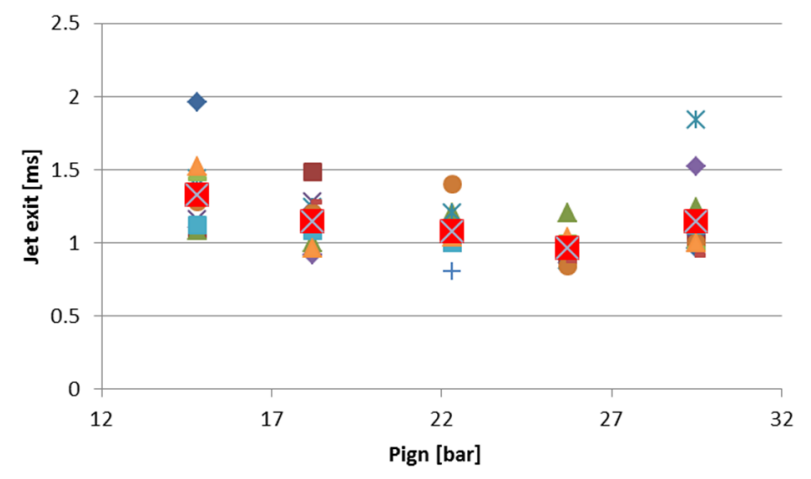

Fig. 2. Time of burning jet emergence into the main chamber for all 12 repetitions per operating point, plotted versus $\mathrm{P}_{\text {ign }}$

The average trend indicates the combustion in the prechamber to be faster with increasing pressure at ignition up to $\mathrm{P}_{\text {ign }}=26$ bar. This is expected to be the result of the combination of increasing reactivity due to the charge temperature and in particular better mixing of prechamber fuel with incoming main chamber charge later in the cycle. A further increase in pressure at ignition to $\mathrm{P}_{\text {ign }}=30$ bar results in a longer time for the jets to emerge, despite the expected increasing temperature of the charge. This can be explained by two possible effects: on the one hand, the reactivity of the mixture near the spark location and during the flame propagation might reduced due to over-leaning of the mixture from the incoming main chamber charge. Alternatively, or in addition, the turbulence intensity caused by the high-velocity incoming flow from the prechamber nozzles during the compression stroke has dissipated significantly at this point, leading to reduced turbulent flame speed and thus delayed jet exit.

What can also be observed from Figure 2 is that the cyclic variation also decreases when approaching the $\mathrm{P}_{\mathrm{ign}}=26$ bar point. The cyclic variation is expected to arise mainly during the early flame development, since the following turbulence-driven flame propagation is expected to be repeatable due to the turbulence being generated by the piston stroke. Thus, the cyclic variation is expected to be connected to small changes in local reactivity around the spark plug; this is supported by the observation that the highest cyclic variation is at the extreme points: $P_{\text {ign }}=15$ bar and $\mathrm{P}_{\text {ign }}=30$ bar. In the former the mixture near the spark plug is rich, while in the latter the mixture is lean. Further analysis of these effects will require the contribution of CFD calculations for these cases, in order to obtain spatial and temporal information concerning the thermochemical conditions in the prechamber. 


\subsection{Main chamber combustion}

Figure 3 shows the time-resolved $\mathrm{OH}^{*}$ chemiluminescence images for representative cycles with $\mathrm{P}_{\text {ign }}=15,23$ and 30 bar. The representative cycles were chosen to be the single realisations of the experiment which have a pressure trace closest to the average pressure trace of all 12 repetitions at these conditions. What is interesting to observe is that the case of $\mathrm{P}_{\mathrm{ign}}=15$ bar shows the highest $\mathrm{OH}^{*}$ signal from the early jets (time instant $1.6 \mathrm{~ms}$ after ignition). This is understood to be due to reactions which occur on the jet surface, from the mixing of the rich jets with the surrounding lean mixture. The intensity then is significantly reduced, before a premixed flame is formed. At this point of main chamber flame propagation higher $\mathrm{OH}^{*}$ intensity
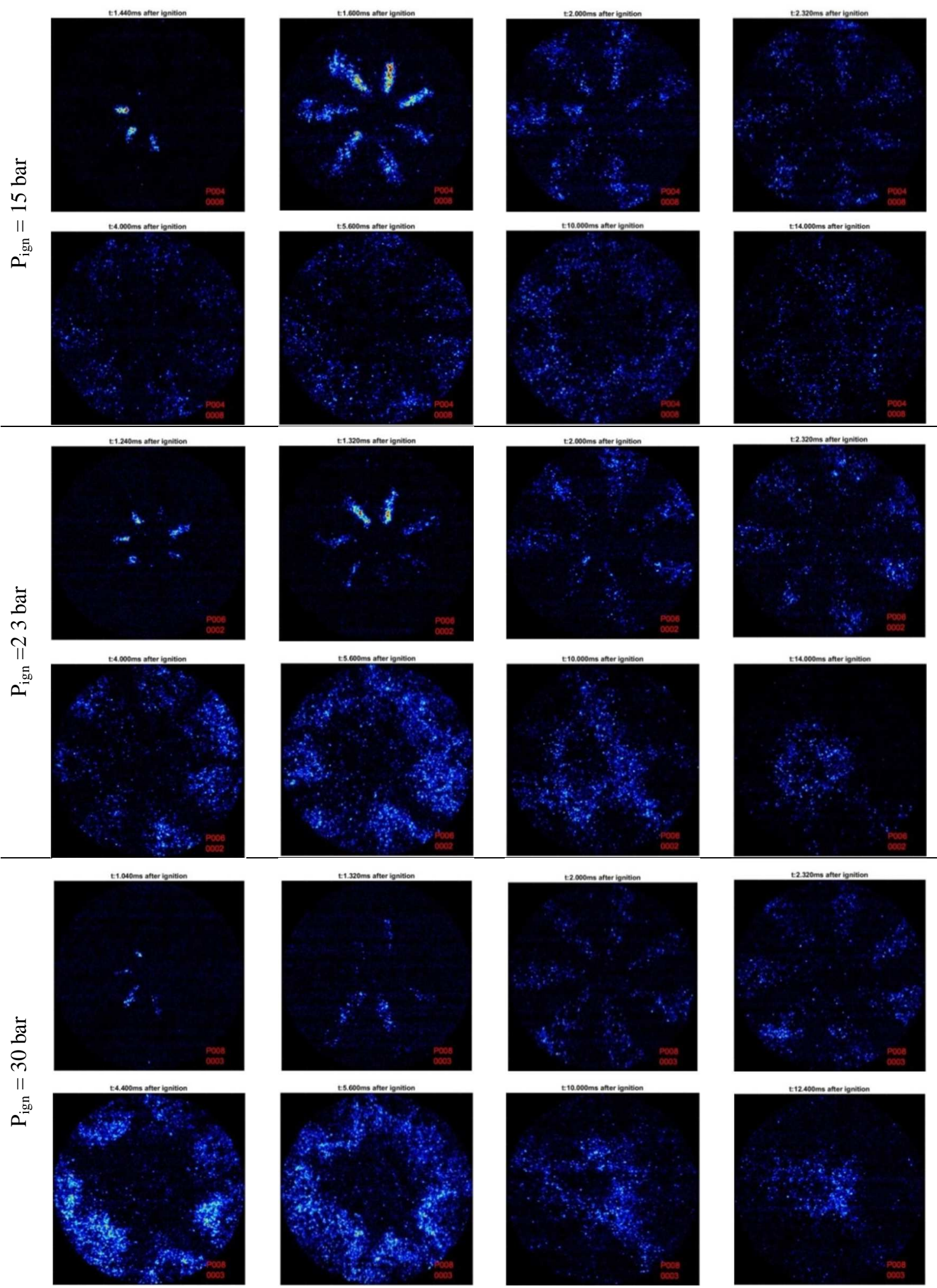

Fig. 3. $\mathrm{OH}^{*}$ chemiluminescence images, showing the prechamber jets and the combustion evolution in the main chamber in cases when ignition occurred at 15 bar (first two lines), 23 bar (middle two lines) and 30 bar (last two lines) 
observed in the cases with later ignition. This indicates that the ignition and subsequent combustion in the main chamber is slower for the early ignition case, possibly due to the reduced reactivity of the main chamber mixture at jet exit (the pressure and as a consequence the charge temperature is lower) and the reduced turbulence intensity induced by the weaker jet.

The observations presented above are supported by the HRR traces of the representative cycles for the same three measurement points, shown in Fig. 4. In the figure the HRRs are plotted against time with the reference at ignition (left plot), as well as with time $=0 \mathrm{~ms}$ at TDC (right plot). These plots allow the comparison of the HRRs in cycle time as well as with respect to ignition timing. The main chamber HRR induced by the jets in the earlier ignited case $\left(\mathrm{P}_{\text {ign }}=15\right.$ bar $)$ shows a slower increase and a significantly reduced peak. What is also noticeable is the delay in the establishment of the premixed flame after the jet exit, which is indicative of the lower reactivity of the main chamber mixture at this jet exit timing. In addition, the possibly lower The two cases with later ignition show very similar HRRs, despite a small delay of the jet exit in the $\mathrm{P}_{\text {ign }}=30$ bar case.

The automotive industry has been intensively modernized in recent years in the aspect of exhaust emissions reduction. Modern passenger vehicles must comply with emission norms in real driving conditions and extended environmental conditions relative to the pre-existing dynamometer tests (variable ambient temperature, pressure, congestion, driving style etc.) [16]. RDE road tests should therefore take into account all possible road situations while maintaining a set specific driving style, so that the obtained emission results are indicative of the vehicle technical characteristics [2]. Thus, there is a number of conditions that must be met in order to perform these test [3].

Vehicle manufacturers continuously introduce modern drive systems in order to meet the stringent emission norms. Despite the increase in the electric vehicles market share, the internal combustion engine continues to be the main propulsion mechanism used in vehicle drive systems (Fig. 1). Their presence will be noticeable in all kinds of hybrid drives $[4,11]$.

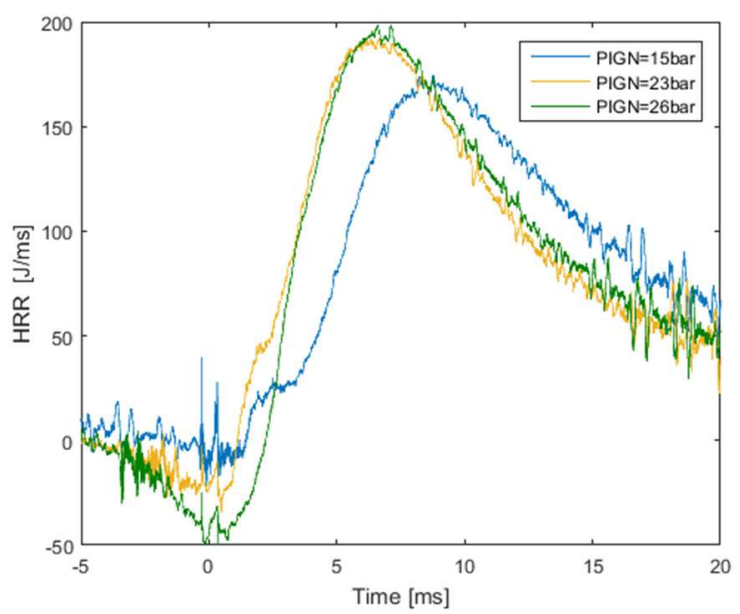

\subsection{Discussion}

In all, the variation of ignition timing (pressure at ignition) showed to significantly affect the prechamber combustion and subsequent main chamber HRR. Early ignition resulted in slower prechamber combustion and the emergence of possibly rich jets early in the cycle, which then lead to a delayed and slower main chamber combustion due to the reduced main chamber reactivity at that time, and possibly low turbulence generation from the jets. Progressively later ignition seemed to produce more stable conditions for prechamber ignition and faster prechamber combustion, up to the point where the trend was reversed possibly due to over-leaning of the prechamber charge through mixing with the incoming main chamber charge and reduced turbulence intensity in the prechamber. Nevertheless the slightly delayed jet emergence timing for the case with late ignition did not seem to affect the main chamber HRR appreciably.

In terms of the relevance to engine operation, it seems clear that the ignition timing in scavenged prechamber engines will need to be coupled to the prechamber injection amount. For early timings, smaller amounts will need to be injected, while in later timings larger amounts are appropriate; this is in order to ensure high-reactivity mixture near the spark plug at ignition, in order to achieve repeatable combustion in the prechamber and low cyclic variation in the main chamber. In addition, high early flame reactivity coupled to high turbulence levels should be sought in order to enhance the main chamber combustion rate and thus engine cycle efficiency.

\section{Conclusions}

In this study the combustion in the prechamber and main chamber for a scavenged prechamber system was investigated experimentally at engine relevant conditions with varying ignition timing in a Rapid Compression Expansion Machine (RCEM). The RCEM allows single parameter variation in addition to optical access into the main chamber for optical diagnostics of the prechamber jets and subsequent flame development. The optical information was obtained using $\mathrm{OH}^{*}$ chemiluminescence measurements,

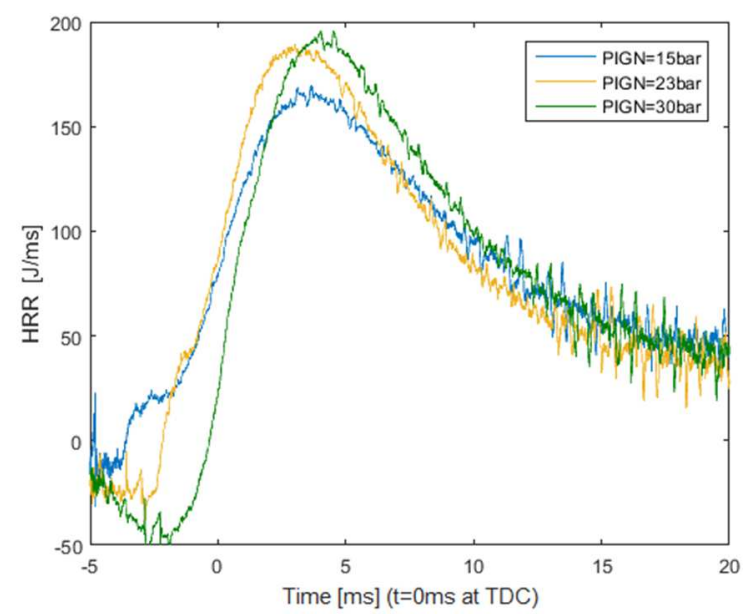

Fig. 4. Heat release rate for the representative cycles of the $\mathrm{P}_{\mathrm{ign}}$ variation plotted against time after ignition (left) and time after TDC (right) 
in order to gain useful insights on the jets exiting the prechamber and combustion propagation in the main chamber. Besides the optical data, pressure measurements were recorded during all the experiments, which allowed the identification of cycle-to-cycle variability and the calculation of heat release rate in the main chamber.

In the present investigation the fuel concentration inside the main chamber $\left(\lambda_{\text {main }}\right)$ and in the prechamber (i.e. the prechamber injection duration) were kept constant, while the pressure at which the ignition was triggered was varied, resulting in an effective change in ignition timing.

The variation of ignition timing (pressure at ignition) showed to significantly affect the prechamber combustion and subsequent main chamber HRR. Early ignition resulted in slower prechamber combustion and the emergence of possibly rich jets early in the cycle, which then result in a delayed and slower main chamber combustion. Progressively later ignition seemed to produce more stable conditions for prechamber ignition and faster prechamber combustion, up to the point where the trend was reversed. This reversal in trend was attributed to over-leaning of the prechamber charge through mixing with the incoming main chamber charge and reduced turbulence intensity in the prechamber with increasingly late ignition timings.

The results indicate that adapted prechamber injection strategies should be followed when varying spark timing in prechamber engines; early ignition should be coupled with low injection amounts, whereas late ignition should be coupled with higher injection amounts. This is expected to lead to faster main chamber combustion and reduced cycleto-cycle variation.

\section{Bibliography}

[1] AL-MAMAR, F.N.A.A., HYNES, J., SHEPPARD, C.G.W. Combustion rate in a dual chamber S.I. engine. Combustion Science and Technology. 1986, 45(1-2), 85-100.

[2] BHANDARI, K. et al. Performance and emissions of natural gas fueled internal combustion engine: A review. 2005.

[3] DALE, J.D., CHECKEL, M.D., SMY, P.R. Application of high energy ignition systems to engines. Progress in Energy and Combustion Science. 1997, 23(5-6), 379-398.

[4] GENTZ, G. et al. A study of the influence of orifice diameter on a turbulent jet ignition system through combustion visualization and performance characterization in a Rapid Compression Machine. Applied Thermal Engineering. 2015 , 81 (Supplement C), 399-411.

[5] GHOLAMISHEERI, M. et al. CFD modeling of an auxiliary fueled turbulent jet ignition system in a Rapid Compression Machine. SAE Technical Paper 2016-01-0599, 2016.

[6] GHOLAMISHEERI, M. et al. Rapid Compression Machine study of a premixed, variable inlet density and flow rate, confined turbulent jet. Combustion and Flame. 2016, 169, 321-332.

[7] GHOLAMISHEERI, M., WICHMAN, I.S., TOULSON, E. A study of the turbulent jet flow field in a methane fueled turbulent jet ignition (TJI) system. Combustion and Flame. 2017, 183(Supplement C), 194-206.

[8] KOTZAGIANNI, M. et al. Experimental and computational investigations of prechamber jet ignition in a Rapid Compression Expansion Machine. 10th Mediterranean Combustion Symposium. 2017. Naples, Italy.

[9] MOREIRA, T.A.A. et al. Characterization of a multicylinder torch ignition system operating with homogenous charge and lean mixture. SAE Technical Paper 2014-360333. 2014.

\footnotetext{
Maria Kotzagianni, MEng. - Institute of Energy Technology, ETH Zurich.

e-mail: Kotzagianni@lav.mavt.ethz.ch
}

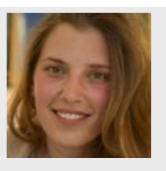

Prof. Konstantinos Boulouchos, DEng. - Institute of Energy Technology, ETH Zurich.

e-mail: Boulouchos@lav.mavt.ethz.ch
[10] MORSY, M.H. Review and recent developments of laser ignition for internal combustion engines applications. Renewable and Sustainable Energy Reviews. 2012, 16(7), 4849-4875.

[11] THELEN, B.C.,TOULSON, E. A computational study of the effects of spark location on the performance of a turbulent jet ignition system. SAE Technical Paper 2016-010608, 2016.

[12] SCHLATTER, S. et al. Experimental study of ignition and combustion characteristics of a diesel pilot spray in a lean premixed methane/air charge using a Rapid Compression Expansion Machine. SAE Technical Paper 2012-01-0825, 2012.

[13] SCHLATTER, S. et al. N-heptane micro pilot assisted methane combustion in a Rapid Compression Expansion Machine. Fuel. 2016, 179, 339-352.

[14] SCHLATTER, S. et al. Comparative study of ignition systems for lean burn gas engines in an optically accessible Rapid Compression Expansion Machine. SAE Technical Paper 2013-24-0112, 2013.

[15] Testem, Technical Manual TeRCM-K48: Rapid Compression Machine for in-cylinder spray development and combustion processes analysis. 2004, Testem - Gesellschaft für Mess- und Datentechnik GmbH.

[16] THELEN, B.C.,TOULSON, E. A computational study on the effect of the orifice size on the performance of a turbulent jet ignition system. Proceedings of the Institution of Mechanical Engineers, Part D: Journal of Automobile Engineering. 2016.

[17] TOULSON, E., SCHOCK, H.J., ATTARD, W.P. A review of pre-chamber initiated jet ignition combustion systems. SAE Technical Paper 2010-01-2263. 2010.

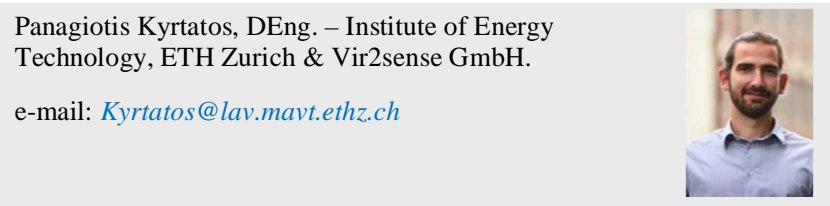

